\title{
High-Grade Basal Cell Adenocarcinoma Arising from the Parotid Gland: A Case Report and Review of the Literature
}

\author{
Çağatay Han Ülkü ${ }^{1}$, Pembe Oltulu², Mustafa Cihat Avunduk ${ }^{2}$ \\ Case Report $>\begin{aligned} & { }^{1} \text { Department of Otorhinolaryngology, Necmettin Erbakan University Meram School of Medicine, Konya, Turkey } \\ & { }^{2} \text { Department of Pathology, Necmettin Erbakan University Meram School of Medicine, Konya, Turkey }\end{aligned}$
}

Abstract

Cite this article as: Ülkü CH, Oltulu P, Avunduk MC. High-Grade Basal Cell Adenocarcinoma Arising from the Parotid Gland: A Case Report and Review of the Literature. Turk Arch Otorhinolaryngol 2017; 55: 187-90.

This study was presented at the $38^{\text {th }}$ Turkish National Congress of Otorhinolaryngology Head and Neck Surgery, 26-30 October 2016, Antalya, Turkey.

Address for Correspondence: Çağatay Han Ülkü E-mail: chanulku@yahoo.com

Received Date: 17.08.2017 Accepted Date: 12.10.2017

(c) Copyright 2017 by 0fficial Journal of the Turkish Society of Otorhinolaryngology and Head and Neck Surgery Available online at www.turkarchotolaryngol.net DOl: 10.5152/ta0.2017.2737
Basal cell adenocarcinomas are exceptionally rare and were first included in the histopathological classification of salivary gland tumors by the World Health Organization in 1991. These tumors are generally described as a low-grade malignancy with rare regional or distant metastasis. However, 48 basal cell adenocarcinoma cases arising from the major salivary glands have been described as high-grade malignancy in the English literature. Surgical excision and possible postoperative radiotherapy is the treatment of choice. Close follow up is mandatory for early detection of

\section{Introduction}

Basal cell adenocarcinoma (BCAC), which was histopathologically classified by the World Health Organization in 1991, is a rare malignant tumor arising from the salivary glands $(1,2)$. To the best of our knowledge, fewer than 600 cases of BCAC arising from the major salivary glands have been reported in the literature up to 2015, and only 48 of them have been described as high-grade BCAC (3).

In this case report, the patient with high-grade $\mathrm{BCAC}$ arising from the parotid gland is presented and the characteristics of the disease are summarized in light of the literature.

\section{Case Presentation}

A 66-year-old female applied to our clinic with a 2-year history of a slow-growing, painless, and semi-mobile mass in the right parotid gland.Physical examination revealed a solid, semi-mobile, $25 \mathrm{~mm} \times 20 \mathrm{~mm}$ soft tissue mass in the right parotid gland. Magnetic resonance imaging (MRI) with contrast revealed a well-defined and minimally heterogeneous mass located on possible local recurrence. A 66-year-old female with high-grade basal cell adenocarcinoma of the parotid gland was presented in this study. Total parotidectomy with protection of the facial nerve integrity and postoperative radiotherapy were performed. At the most recent follow-up examination, 24 months after the surgery, the patient had no complaints and there was no sign of disease recurrence.

Keywords: Basal cell adenocarcinoma, salivary gland, parotid, treatment

the superficial lobe of the parotid gland, measuring $22 \mathrm{~mm}$ x $18 \mathrm{~mm}$ (Figure 1). The neck was free of the disease. Fine needle aspiration biopsy did not enable us to make a diagnosis of malignancy. Written informed consent was received from the patient, and the tumor was resected by superficial parotidectomy with preservation of the facial nerve.

Microscopically, basaloid cell islands were observed. Dark basophilic cells were often located in the peripheral area, whereas pale basophilic cells were located in the central area (Figure 2). Alpha chymotrypsin, mucin, S 100 (Figure 3), and p63 (Figure 4) staining led us to make a diagnosis of BCAC (solid type). Furthermore, the existence of atypical mitotic figures, pleomorphism, vascular, and perineural invasion, necrosis, solid growth pattern, invasion into the parotid gland, and high $\mathrm{Ki}-67$ index (80\%) (Figure 5) were the indicators of a highgrade tumor. Thus the final histopathological diagnosis was high-grade BCAC (solid type). According to the decision of the institution's tumor-board, the patient underwent additional 


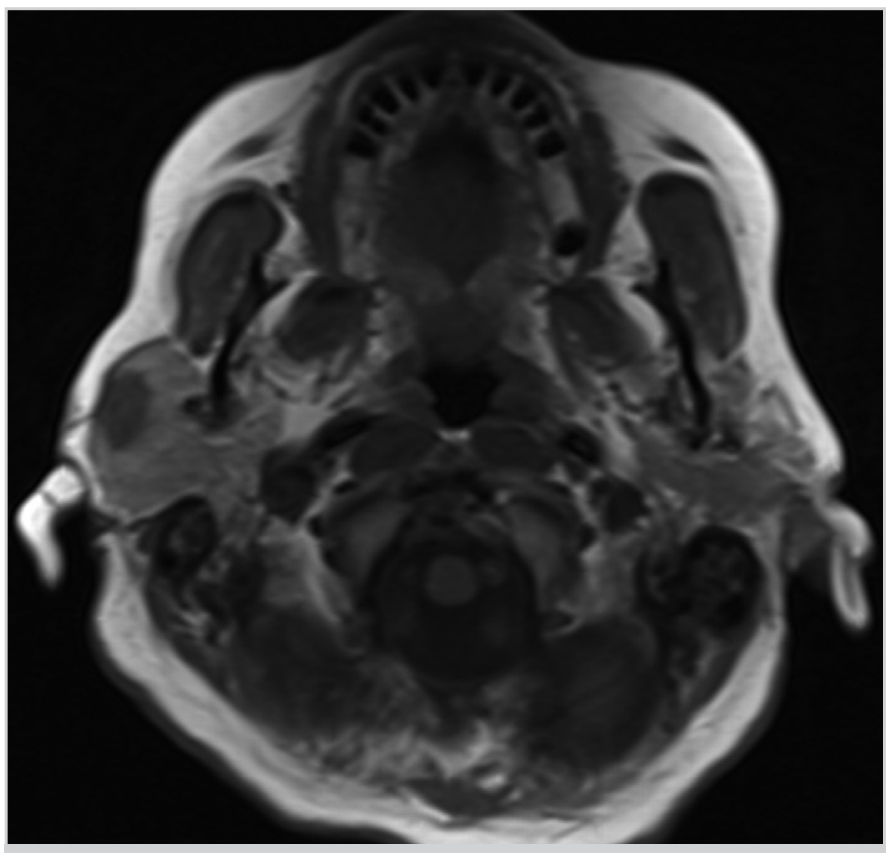

Figure 1. Axial MRI appearance of the mass

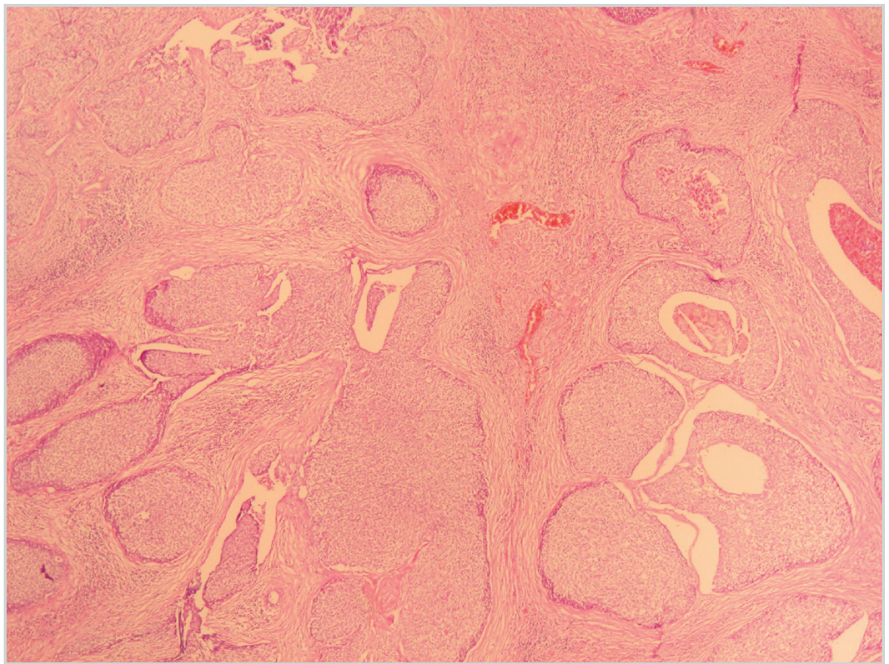

Figure 2. Histopathological appearance with hematoxylin\&eosin staining X4

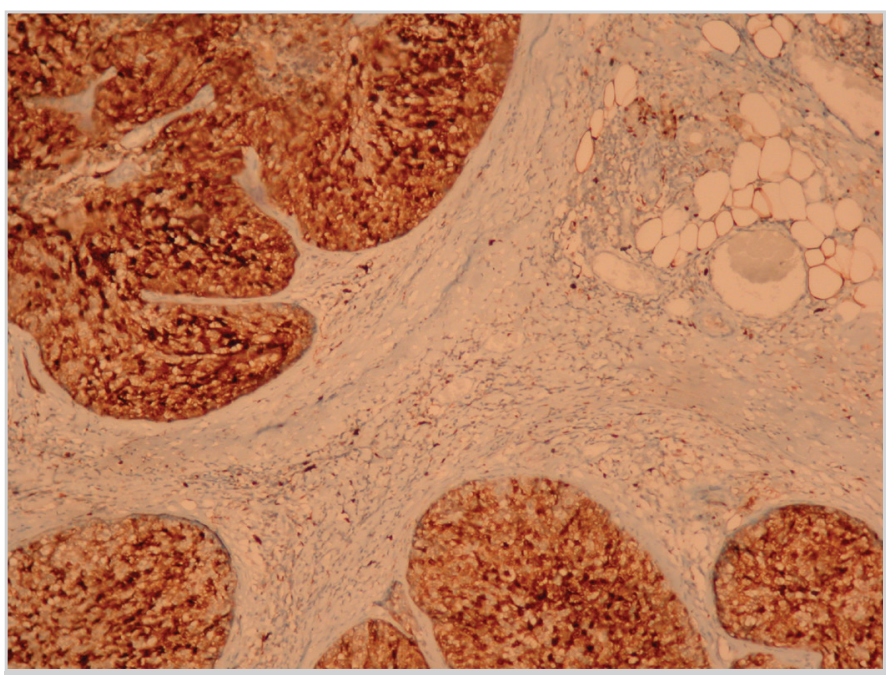

Figure 3. Histopathological appearance with S100 staining X10

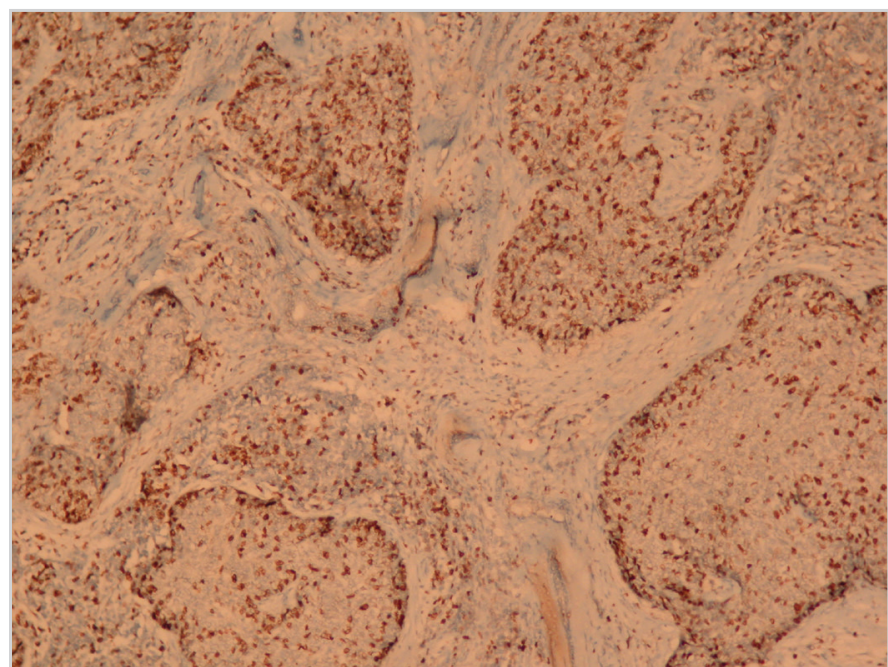

Figure 4. Histopathological appearance with p63 staining X10

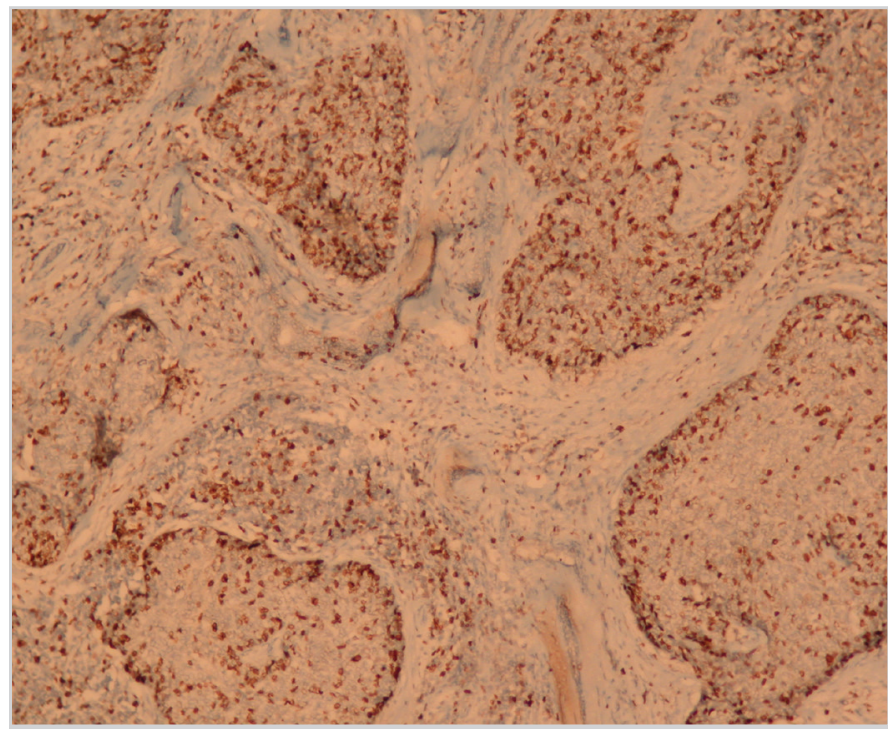

Figure 5. Histopathological appearance with high Ki-67 index (80\%) X10

surgery and total parotidectomy with preservation of the facial nerve. Histopathologically, there was no tumor in the deep parotid lobe. Treatment was completed by postoperative radiotherapy. At the most recent follow-up examination, 24 months after the last surgery, there was no sign of disease recurrence.

\section{Discussion}

Basal cell adenocarcinoma composes only $1.4 \%$ of all major salivary gland malignant tumors, and it primarily arises from the parotid gland (88\%) followed by the submandibular $(11.2 \%)$ and sublingual (0.8\%) glands. This tumor is also referred to as carcinoma ex-monomorphic adenoma, basaloid salivary gland carcinoma, and malignant basal cell tumor (3). Minor salivary glands are less common locations for BCAC, which is most frequently seen in the hard palate and buccal mucosa $(4,5)$. These tumors mostly arise de novo $(77 \%)$, but they might also arise from preexisting basal cell adenomas (23\%) (2). 
Clinically, BCAC is a slowly enlarging, non-tender mass (3). The average symptom duration prior to diagnosis has been reported to be 1.8 years by Ellis and Wiskovitch (6). Additional cutaneous adnexal lesions are also observed in about $10 \%$ of BCAC cases. According to the retrospective database review of The National Cancer Database in the US between 1998 and 2012 by Zhan et al. (3) $47.3 \%$ of the tumors were $2 \mathrm{~cm}$ to $4 \mathrm{~cm}$ in diameter, and $35.8 \%$ of them were less than $2 \mathrm{~cm}$ in diameter. The average age at diagnosis is 64 years (range 18 years to 92 years).

Histopathologically, BCAC tumors are classified as solid, membranous, tubular, or trabecular. The majority of them are the solid type, which has much more perineural and intravascular growth potential, and 19 solid, six membranous, three trabecular, and one tubular type BCAC were reported by Ellis and Wiskovitch (6) in their series of 29 cases. Moreover, regional and systemic metastasis rates are also higher for the solid type. Thus, the classification of BCAC might influence the treatment protocol and prognosis $(2,6)$.

Basal cell adenocarcinoma is generally described as a lowgrade malignancy and prognosis is usually good. In 45 cases with BCAC, $8 \%$ had cervical lymph node metastases, $4 \%$ had distant metastases, and $2 \%$ resulted in exitus as reported by Muller et al. (2) for a long follow-up period. In another study, regional and distant (lungs, scalp, manubrium, etc.) metastasis rates were reported as $11.9 \%$ and $1.8 \%$, respectively, by Zhan and Lentsch (3). Surgical excision with free margins is the most common treatment of choice (45.1\%). This is followed by surgery and postoperative radiotherapy (39.4\%) and by only close follow up without any treatment (6.9\%) (3).

Zhan et al. (3) described 48 high-grade (solid type, overexpression of p53 and high $\mathrm{Ki}-67$ index) BCAC cases (9.43\%) in a database review of the National Cancer Database. Another review of $11 \mathrm{BCAC}$ cases was performed, and solid pattern and overexpression of $\mathrm{Ki}-67$ index and $\mathrm{p} 53$ were observed on histopathological examination by Nagao et al. (7). The clinical and histopathological features of these high-grade BCACs are more aggressive. Extraglandular invasion and T3- or T4-stage tumors might be seen more frequently, and surgery and postoperative radiotherapy are more often performed as a treatment for these cases. Even when the surgical margins are free of the tumor, BCAC tends to make a local recurrence (16.7\%-50\%) between 6 and 24 months after the surgery. Thus, long-term follow up is required $(2,3,7,8)$.

Clinical and histopathological regional metastasis rates were reported as $6.7 \%$ and $11.9 \%$ for BCAC, respectively, by Zhan et al. (3) Furthermore, the occult nodal metastasis rate was reported as $5.7 \%$. Thus, neck dissection is not required for N0 neck cases.

Solid-type adenoid cystic carcinoma, cutaneous basal cell carcinoma, basal cell adenoma, and small cell carcinoma should all be taken into consideration for differential diagnosis $(3,7,8)$.

In this presentation, the patient with high-grade $\mathrm{BCAC}$ of the parotid gland was staged as T2NOM0. The patient's treatment was completed by total parotidectomy and postoperative radiotherapy due to the aggressive features of the solid-type highgrade BCAC. Facial nerve integrity and function were protected. At the most recent follow-up examination, 24 months after the last surgery, the patient had no complaints and there were no signs of disease recurrence.

\section{Conclusion}

Clinical and histopathological features of high-grade $\mathrm{BCACs}$ (solid type) are more aggressive. Treatment generally includes surgery and postoperative radiotherapy. Even when the surgical margins are free of the tumor, BCAC tends to make a local recurrence. Thus, long-term follow up is required.

Informed Consent: Written informed consent was obtained from the patient who participated in this study.

Peer-review: Externally peer-reviewed.

Author Contributions: Concept - Ç.H.Ü., P.O., M.C.A.; Design - Ç.H.Ü., P.O., M.C.A.; Supervision - Ç.H.Ü., P.O., M.C.A.; Resource - Ç.H.Ü., P.O., M.C.A.; Materials - Ç.H.Ü., P.O., M.C.A.; Data Collection and/or Processing - Ç.H.Ü., M.C.A.; Analysis and/or Interpretation - Ç.H.Ü., M.C.A.; Literature Search - Ç.H.Ü.; Writing - Ç.H.Ü.; Critical Reviews - Ç.H.Ü., P.O., M.C.A.

Conflict of Interest: No conflict of interest was declared by the authors.

Financial Disclosure: The authors declared that this study has received no financial support.

\section{References}

1. Seifert G, Batsakis JG, Brocheriou C, Cardesa A, Dardick I, Ellis GL, et al. World Health Organisation International Histological Classification of Tumours. Histologic Classification of Salivary Gland Tumours. 2nd edition. Berlin: Springer-Verlag, 1991: 9-13, 24-6.

2. Muller S, Barnes L. Basal cell adenocarcinoma of the salivary glands. Report of seven cases and review of the literature. Cancer 1996; 78: 2471-7.

3. Zhan KY, Lentsch EJ. Basal cell adenocarcinoma of the major salivary glands: A population-level study of 509 cases. Laryngoscope 2016; 126: 1086-90. [CrossRef]

4. Gross M, Maly B, Goldfarb A, Eliashar R. Basal cell adenocarcinoma in a buccal minor salivary gland. Acta Otolaryngol 2004; 124: 213-6. [CrossRef]

5. Ward BK, Seethala RR, Barnes EL, Lai SY. Basal cell adenocarcinoma of a hard palate minor salivary gland: case report and review of the literature. Head Neck Oncol 2009; 1: 41. [CrossRef]

6. Ellis GL, Wiscovitch JG. Basal cell adenocarcinomas of the major salivary glands. Oral Surg Oral Med Oral Pathol 1990; 69: 461-9. [CrossRef] 
7. Nagao T, Sugano I, Ishida Y, Hasegawa M, Matsuzaki O, Konno A, et al. Basal cell adenocarcinoma of the salivary glands: comparison with basal cell adenoma through assessment of cell proliferation, apoptosis, and expression of p53 and bcl-2. Cancer 1998; 82: 439-47.
8. Wilson TC, Robinson RA. Basal cell adenocarcinoma and basal cell adenoma of the salivary glands: a clinicopathological review of seventy tumors with comparison of morphologic features and growth control indices. Head and Neck Pathol 2015; 9: 205-13.[CrossRef] 